\title{
Effect of hypoxia on angiogenesis related factors in glioblastoma cells
}

\author{
MARWAN EMARA $^{1,2}$ and JOAN ALLALUNIS-TURNER ${ }^{1}$ \\ ${ }^{1}$ Department of Oncology, University of Alberta and Alberta Health Services, Cross Cancer Institute, Edmonton, \\ Alberta T6G 1Z2, Canada; ${ }^{2}$ Center for Aging and Associated Diseases, Zewail City of Science and Technology, Cairo, Egypt
}

Received December 4, 2013; Accepted January 21, 2014

DOI: 10.3892/or.2014.3037

\begin{abstract}
Pathological angiogenesis is a characteristic feature of glioblastoma multiforme (GBM) where the balance between pro-angiogenic and anti-angiogenic factors are shifted towards the pro-angiogenic phenotype. In this study we sought to determine whether angiostatins are expressed by GBM cells and whether their expression along with other related factors [matrix metalloproteinase (MMP)-2, MMP-9, and collagen type I $\alpha 1$ (COLIA1)] are altered by hypoxia and/or correlated with the levels of cancer stem cell marker CD133. Using qRT-PCR, western blotting, and gelatin zymography, we examined the expression of angiostatins, MMP-2, MMP-9, COLIA1 and CD133 in GBM cell lines cultured under aerobic conditions and hypoxia. Expression levels of MMP-2 and MMP-9 were significantly induced by hypoxia. Angiostatins were detected in all GBM cell lines and were increased by hypoxia while the angiostatin isoform of $38-\mathrm{kDa}$ was the most abundant in GBM cells under aerobic and hypoxic conditions. COLIA1 and CD133 were significantly increased in several GBM cell lines under hypoxia. Despite expression and upregulation of anti-angiogenic factors (e.g. angiostatins) in GBM cells, they are overwhelmed by the overexpression of a larger number of angiogenic factors that shift the angiogenic balance towards the pro-angiogenic phenotype. Thus, an exogenous administration of anti-angiogenic factors may be required to improve the treatment of GBM tumors.
\end{abstract}

\section{Introduction}

In adults, the formation of new blood vessels from pre-existing ones is defined as angiogenesis (e.g. in the female reproductive system and wound healing) (1). It is a physiologically balanced process, regulated by pro-angiogenic [e.g. matrix metallopro-

Correspondence to: Dr Marwan Emara, Department of Oncology, University of Alberta and Alberta Health Services, Cross Cancer Institute, 11560 University Avenue, Edmonton, AB T6G 1Z2, Canada E-mail: memara@ualberta.ca

Key words: hypoxia, glioblastoma multiforme, angiogenesis, angiostatin, matrix metalloproteinase, collagen type I $\alpha 1$ teinases (MMPs), vascular endothelial growth factor (VEGF) and hypoxia inducible factor (HIF)-1 $\alpha$ ] and anti-angiogenic (e.g. MMPs and angiostatins) factors (2). Disrupted balance between these factors has been implicated in numerous pathological conditions such as cardiovascular diseases, rheumatoid arthritis, psoriases, diabetic retinopathy and cancer (3).

In the US, malignant gliomas constitute $80 \%$ of malignant tumors in the central nervous system (CNS) where glioblastoma multiforme (GBM) tumors represent more than half of gliomas (4), with 2-year survival rates of $\sim 10$ and $25 \%$ in patients treated with radiotherapy and radiotherapy plus temozolomide, respectively (5). Hypoxia-induced necrosis and neovascularization are pathognomonic features of GBM tumors (6) where tumor hypoxia has been shown to induce several genes that encode essential proteins for angiogenesis, cell survival, genetic instability, chemotherapy and radiation resistance (reviewed in ref. 7). Furthermore, the extreme heterogeneity and infiltrative properties of GBM cells make their treatment nearly impossible even with aggressive multimodality therapeutic approaches (6).

MMP-2 and MMP-9 are zinc-dependent endopeptidases. They degrade type IV collagen, gelatin and fibronectin in the extracellular matrix (ECM) (8) to allow the expansion of new blood vessels. By contrast, MMP-2 (9) and MMP-9 (10) generate angiostatin isoforms by proteolytic cleavage of plasminogen. Unlike MMP-2, MMP-9 is not constitutively expressed by many cell types and does not cleave type I collagen (11). However, expression of both MMP-2 and MMP-9 has been reported in both vascular endothelial cells (12) and GBM cells (13). Type I collagen is the most abundant collagen molecule within the collagen family (14). It is an ECM component that consists of an $\alpha 1(\mathrm{I})$ and $\alpha 2(\mathrm{I})$ chain (15) and has been reported to be deposited by glioma cell lines (16). The procollagen type I $\alpha 1$ (COLIA1) gene has been found to suppress tumor growth and invasion of glioma (17), and aids potentially in the histopathological grading of human glioma (18). On the other hand, it is implicated in MMP-2 activation through induction of membrane type 1 MMP $(19,20)$.

Although plasminogen, the angiostatin precursor, is synthesized primarily in the liver and is delivered to other tissues, its synthesis has been reported in other tissues (e.g. the cornea) (21). The vast majority of published data have focused on the local administration of recombinant angiostatin that may inhibit angiogenesis and suppress tumor progression 
in preclinical studies of GBM tumors (22). Although there is scarce information on the endogenous expression of angiostatin protein by GBM cells, a microarray database (http://www.ebi.ac.uk/arrayexpress/) showed that human plasminogen (PLG) was overexpressed in 2 experiments (accession no. E-GEOD-23806 and E-GEOD-4290), underexpressed in 1 experiment (accession no. E-GEOD-23806) and non-differentially expressed in 4 experiments (accession no. E-GEOD-23806, E-GEOD-4290, -4412, -7696 and -E-MEXP-567) in human GBM cells.

Since the survival, growth and metastasis of GBM cells depend mainly on the formation of new blood vessels (23), in this study we examined the levels of MMP-2 and MMP-9, angiostatin, COL1A1 and CD133 expression in GBM cells exposed to physiologically relevant levels of hypoxia. Additionally, we examined the correlation between CD133 and levels of other measured parameters.

\section{Materials and methods}

Cell lines and culture conditions. The origin and characterization of the GBM cell lines have been previously published: the M059J (ATCC no. CRL2366) and M010b cell lines are hypoxia-sensitive $(24,25)$; the M059K (ATCC no. CRL-2365) and M006x cell lines are hypoxia-tolerant (26). The U87R and U87T cell lines are established GBM cell lines (27) and were kindly provided by Dr Donna Senger (University of Calgary). Their relative sensitivity to hypoxia has not been determined. All cells were maintained as monolayer cultures in DMEM/F12 media supplemented with $10 \%$ fetal calf serum and $1 \mathrm{mM}$ L-glutamine in a humidified atmosphere of $5 \% \mathrm{CO}_{2}$ in air at $37^{\circ} \mathrm{C}$. All tissue culture supplies were purchased from Gibco.

Generation of hypoxia in vitro. To examine the effect of hypoxia on the expression of angiostatins, MMP-2 and MMP-9 proteins and COLIA1 and CD133 mRNA, hypoxia was generated using a de-gassing manifold as described by Koch et al (28). Cells $\left(\sim 2 \times 10^{5}\right)$ at the exponential phase were seeded onto $60-\mathrm{mm}$ glass plates and then incubated under standard laboratory culture conditions $\left(5 \% \mathrm{CO}_{2}\right.$ in air) for 4 days. The medium was then replenished, and the plates were transferred to aluminum chambers from which the air was evacuated and then replaced with $5 \% \mathrm{CO}_{2} /$ balanced $\mathrm{N}_{2}$ until an $\mathrm{O}_{2}$ tension of $0.6 \%$ was achieved. The sealed, air-tight aluminum chambers were then incubated at $37^{\circ} \mathrm{C}$ for $48 \mathrm{~h}$. By the end of the incubation time, the aluminum chambers were unsealed, the tissue culture plates removed and then total RNA and cell proteins were isolated.

RNA extraction and reverse transcription. The RNeasy Mini Kit (Qiagen) was used to isolate total RNA from the GBM cultured cell lines. Reverse transcription (RT) was carried out with $0.1-1 \mu \mathrm{g}$ total $\mathrm{RNA} / 20 \mu \mathrm{l}$ reaction volume using the QuantiTect reverse transcription kit (Qiagen).

Quantitative real-time reverse transcription-PCR ( $q R T$ $P C R)$. qRT-PCR analysis was carried out using a 7900HT Fast Real-Time PCR System using TaqMan Fast Universal PCR Master Mix and validated TaqMan ${ }^{\circledR}$ gene expression assays (both from Applied Biosystems) for COLIA1 (assay ID: Hs01076780_g1) and PROM1 (CD133) genes (assay ID: Hs01009250_m1). Human 18S rRNA gene (part no: 4333760T; Applied Biosystems) was used as the endogenous control. Amplification data were analyzed with SDS RQ Manager 1.2 software (Applied Biosystems). Fold-changes in gene expression normalized to the endogenous control gene (18S rRNA) and relative to normoxic baseline were quantified using the $2^{-\Delta \Delta C T}$ method where,

$2^{-\Delta \mathrm{CT}}[($ hypoxic sample - endogenous control) - $\Delta \mathrm{CT}$ (normoxic sample - endogenous control)]

Gelatin zymography. The activity levels of MMP-2 and MMP-9 in M006x, M059J, M059K, M010b, U87R and U87T cells were determined by gelatin zymographic analysis as previously described (29). Briefly, cells were washed 4 times with phosphate-buffered saline (PBS), and wholecell lysates were prepared using complete Lysis-M buffer (Roche Diagnostics). Protein content was determined using a protein assay kit (Pierce). Samples were mixed with $6 \mathrm{X}$ sample buffer and electrophoresed on $10 \%$ sodium dodecyl sulfate-polyacrylamide gel electrophoresis (SDS-PAGE) containing gelatin ( $2 \mathrm{mg} / \mathrm{ml}$, Sigma cat. no. G-8150). Each sample (20 $\mu \mathrm{g}$ protein) was analyzed in duplicate. Pre-stained protein markers were used. Following electrophoresis, the gels were washed 3 times (20 min each) in $2.5 \%$ Triton X-100 to remove SDS and then incubated in Tris-buffer $[0.05 \mathrm{M}$ Tris- $\mathrm{HCl}$ (Invitrogen) ( $\mathrm{pH} 7.5$ ) containing $0.01 \mathrm{M} \mathrm{CaCl}_{2}, 0.2 \mathrm{M}$ $\mathrm{NaCl}$ and $0.05 \% \mathrm{NaN}_{3}$ ] at $37^{\circ} \mathrm{C}$ for $20 \mathrm{~h}$. The gels were stained with $0.05 \%$ Coomassie Brilliant Blue G-250 (Sigma) in 25\% methanol and $10 \%$ acetic acid for $2 \mathrm{~h}$ with shaking at room temperature, and then destained with $4 \%$ methanol and $8 \%$ acetic acid for $30 \mathrm{~min}$. Finally, the gels were rinsed in distilled water containing $10 \%$ glycerol prior to drying between sheets of cellophane (Sigma). The zymograms were scanned, and the gelatinolytic bands were analyzed using Quantity One 1-D Analysis software (Bio-Rad Laboratories, Hercules, CA, USA). The activity of the gelatinolytic bands of MMP-2 and MMP-9 (present in $20 \mu \mathrm{g}$ protein) was determined and expressed in arbitrary units.

Western blotting. To detect angiostatin proteins, the M006x, M059J, M059K, M010b, U87R and U87T cells were washed 4 times with PBS. Whole-cell lysates were prepared using complete Lysis-M buffer. The protein content was determined using a protein assay kit. Equal amounts of protein $(50 \mu \mathrm{g})$ were resolved using $12 \%$ SDS-PAGE under reducing conditions and electrotransferred to polyvinylidene difluoride (PVDF) membranes (Bio-Rad). All western blot analysis procedures were carried out at room temperature. Membranes were blocked with $5 \%$ goat serum for $1 \mathrm{~h}$, and then incubated with mouse anti-human angiostatin monoclonal antibody ( $2 \mu \mathrm{g} / \mathrm{ml}$; cat. no. MAB926; R\&D Systems, Inc., Minneapolis, MN, USA) for $2 \mathrm{~h}$. Membranes were washed and then incubated with polyclonal goat anti-mouse IgGs (1:2,500; code no. P 0447; DakoCytomation Denmark A/S, Denmark) for $1 \mathrm{~h}$.

For the loading control, membranes were stripped by incubation in Tris- $\mathrm{HCl}$ buffer ( $\mathrm{pH}$ 6.7) containing $100 \mathrm{mM}$ 2-mercaptoethanol and $2 \% \mathrm{SDS}$ at $50^{\circ} \mathrm{C}$ for $30 \mathrm{~min}$. Membranes were blocked with $5 \%$ goat serum for $1 \mathrm{~h}$ and then incubated with mouse anti-human $\alpha$-tubulin monoclonal 
antibody (1:5,000; product no. T 6199; Sigma) for $2 \mathrm{~h}$. Membranes were washed and then incubated with goat antimouse IgG $(1: 2,500)$ antibodies for $1 \mathrm{~h}$.

Bound proteins were detected using chemiluminescence reagents (SuperSignal West Pico Chemiluminescent Substrate; Thermo Scientific, Rockford, IL, USA) and visualized by exposure to X-ray film (Fuji Photo Film, Japan) that was developed using a Kodak X-OMAT 2000A processor (Eastman Kodak Company, Japan).

Statistics. Data are expressed as means \pm standard error from 4 replicate experiments. Statistical analyses were performed using SigmaPlot 12 software (Systat Software Inc., Chicago, IL, USA). Differences between groups were compared using an unpaired t-test or Mann-Whitney rank-sum test based on the normality and equal variance tests.

\section{Results}

Enzymatic activity of MMP-2 and MMP-9. Gelatin zymographic analysis of MMP-2 and MMP-9 in the cell lysates of GBM cells revealed differential expression in the activity levels of pro- and active forms of both MMPs under aerobic and hypoxic conditions (Fig. 1). Activity levels of pro-MMP-9 were undetectable in all GBM cells under aerobic conditions whereas under hypoxic conditions it was detected in the M006x cells (Fig. 1A). Active MMP-9 was detected in M006x (Fig. 1A) and M010b (Fig. 1D) cells under aerobic conditions, and in M006x, M059J, M059K, M010b and U87R cells (Fig. 1A-E) under hypoxic conditions. In the M010b cells, the activity level of active MMP-9 was significantly $(\mathrm{P}=0.004)$ higher under hypoxic conditions (Fig. 1D). No activity of MMP-9 was detected in U87T cells (Fig. 1F). Under both aerobic and hypoxic conditions, pro-MMP-2 was detected in the U87T cells (Fig. 1F) and its activity was significantly $(\mathrm{P}=0.004)$ higher under hypoxic conditions, whereas no activity of pro-MMP-2 was detected in the other GBM cells. Under aerobic and hypoxic conditions, activity levels of active MMP-2 were detected in all GBM cells. Compared with aerobic conditions, active MMP-2 was significantly higher in M059J ( $\mathrm{P} \leq 0.001$; Fig. 1B), M059K (P $\leq 0.001$; Fig. 1C) and U87T ( $\mathrm{P}=0.01$; Fig. 1F) cells under hypoxia. No significant changes were observed in M006x, M010b and U87R cells. In comparison to aerobic conditions, total MMP-2 and MMP-9 (pro- and active forms) were significantly higher under hypoxic conditions in M006x ( $\mathrm{P}=0.018)$, M059J $(\mathrm{P} \leq 0.001)$, M059K $(\mathrm{P} \leq 0.001), \mathrm{M} 010 \mathrm{~b}(\mathrm{P} \leq 0.001), \mathrm{U} 87 \mathrm{R}(\mathrm{P} \leq 0.001)$ and U87T (P $\leq 0.003)$ cells (Fig. 1A-F).

Expression of angiostatin proteins in GBM cells. Western blot analysis revealed three proteolytic isoforms of 38, 43 and $50 \mathrm{kDa}$ that are believed to represent the first three (K1-3), four (K1-4) and five (K1-5) kringle domains of plasminogen, respectively (30-32), with abundance of the 38-kDa isoform under both aerobic $(46.2 \pm 1.8 \%)$ and hypoxic $(44.5 \pm 1 \%)$ conditions relative to total angiostatins. Compared with aerobic conditions, hypoxia treatment significantly increased angiostatin of $50-\mathrm{kDa}$ in the M059K cells $(\mathrm{P}=0.005$; Fig. $2 \mathrm{C})$, 43-kDa in the M059J ( $\mathrm{P}=0.04$; Fig. 2B) and M010b $(\mathrm{P}=0.003$;

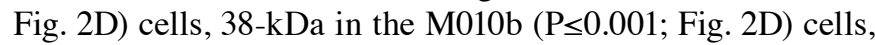

and total angiostatins (55-, 43- and 38-kDa) in the M059K $(\mathrm{P}=0.02$; Fig. 2C) and M010b ( $\mathrm{P}=0.007$; Fig. 2D) cells.

Expression of COLIA1 and CD133 mRNA in GBM cells. In agreement with others (18), COLIA1 mRNA was detected in all GBM cells under aerobic conditions. Hypoxia significantly increased COLIA1 expression in M059J $(\mathrm{P}=0.002)$, M059K $(\mathrm{P}=0.002), \mathrm{M} 010 \mathrm{~b}(\mathrm{P}=0.025), \mathrm{U} 87 \mathrm{R}(\mathrm{P}=0.029)$ and U87T ( $\mathrm{P} \leq 0.001)$ cells (Fig. 3 ).

Consistent with previous reports $(33,34)$, CD133 mRNA was detected in all GBM cells under aerobic conditions. Hypoxic conditions significantly increased the CD133 mRNA in M059J $(\mathrm{P}=0.007)$, U87R $(\mathrm{P} \leq 0.001)$ and U87T $(\mathrm{P}=0.001)$ cells (Fig. 4).

Notably, activity levels of MMP-2, MMP-9 or total MMP-2 and -9 , angiostatins and COLIA1 were not correlated with the GBM cell characteristics of sensitivity (M059J and M010b) or tolerance (M006x and M059K) to hypoxia $(24,25)$. In addition, none of the aforementioned parameters were correlated with CD133.

\section{Discussion}

Pathological angiogenesis is a characteristic feature of GBM tumors as newly formed blood vessels are crucial to their growth and metastasis (35). To acquire and maintain neovascularization, the angiogenic balance should be altered and shifted towards a pro-angiogenic phenotype that was found to be intensified by the hypoxic nature of GBM tumors. The pro-angiogenic phenotype is associated with malignant transformation and is initialized by VEGF induction by transcription factors HIF-1 (36) and others such as ETS-1 (37) and STAT-3 (38). Consequently, the vascular permeability increases followed by migration and proliferation of endothelial cells that requires deposition of the degraded pro-angiogenic matrix for newly formed vessels (23).

Accumulating evidence has shown that increased expression of either MMP-2, MMP-9 or both in GBM cells enhances their invasiveness and angiogenesis $(13,39)$, and this may be augmented by hypoxia (40). Consistently, here, we report deferential expression of gelatinases in GBM cells with significant expression of MMP-2 and both under aerobic conditions and hypoxia, respectively. In agreement with another study (41), under hypoxia MMP-2 and MMP-9 were predominantly expressed in active forms. However, the absence of detectable expression of pro-, active, or both MMP-9 forms in some GBM cells under aerobic or hypoxic conditions could be explained by lower sensitivity of gelatin zymography or heterogeneity of GBM cells (42).

Angiostatins, the proteolytic fractions of plasminogen that are present in the blood of cancer patients and animals bearing tumors disappear after surgical tumor removal (43). On the other hand, MMP-2 and MMP-9 are among the proteolytic enzymes expressed by cancer cells and are implicated in angiostatin generation from the circulating plasminogen $(9,10)$ by proteolytic cleavage at specific sites that are different for other proteolytic enzymes (30). However, no evidence supports the direct expression of angiostatins by cancer cells themselves (9). In the present study, we are the first to report expression and hypoxic upregulation of angiostatins in 
A
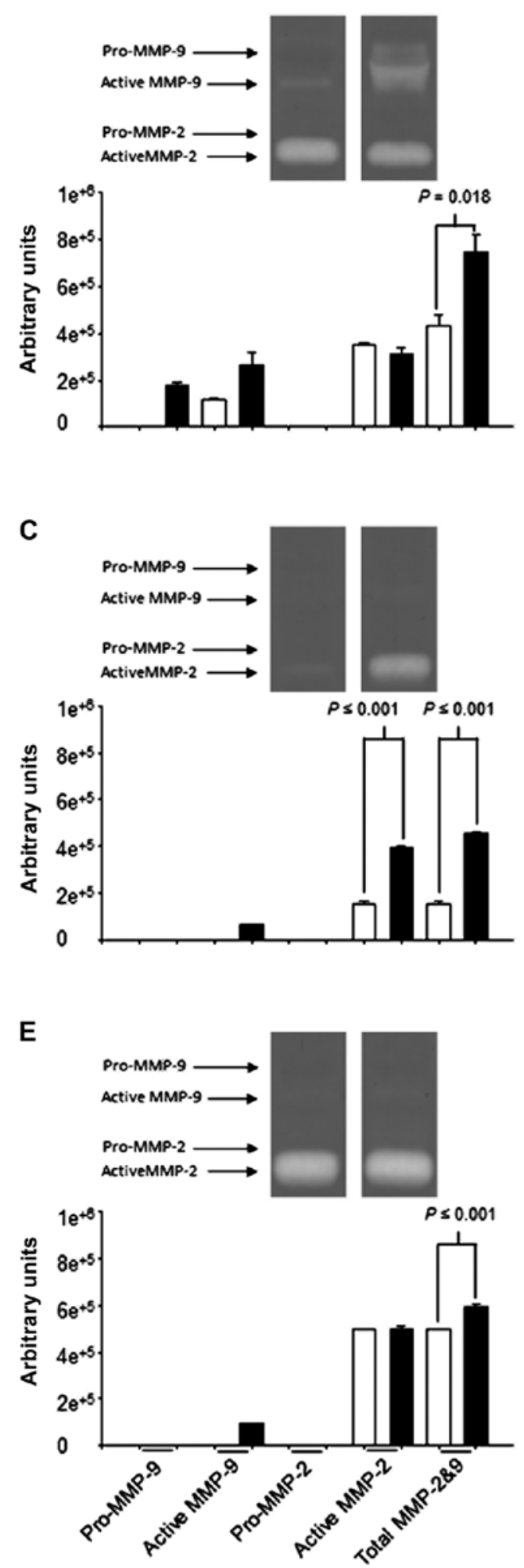

B
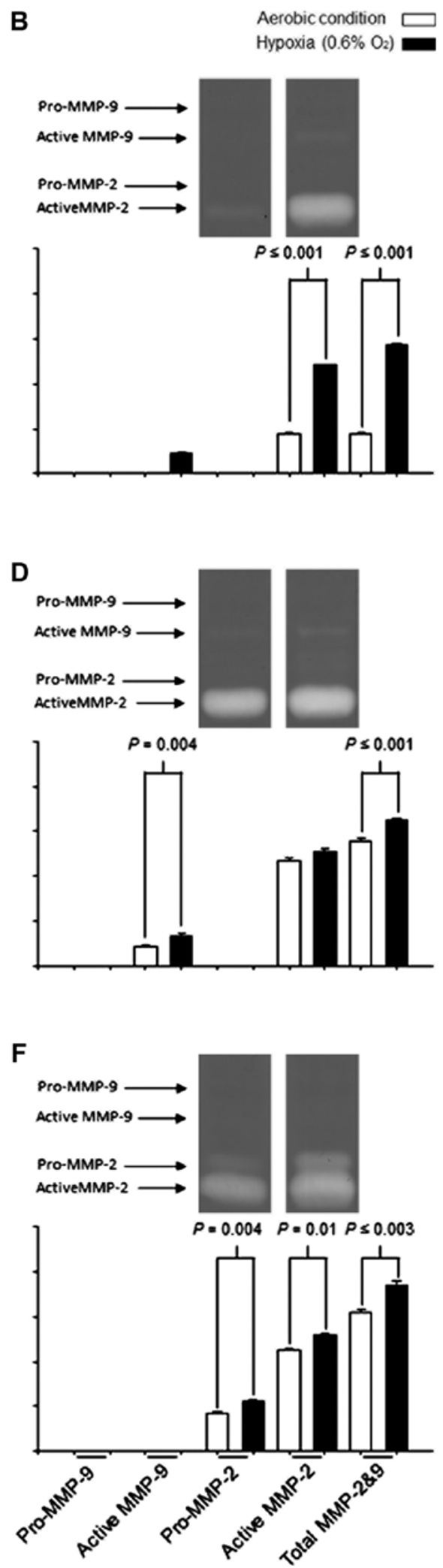

Figure 1. Representative zymograms and activity levels of MMP-2 and MMP-9 in GBM cells. (A) M006x, (B) M059J, (C) M059K, (D) M010b, (E) U87R and (F) U87T cells. Activity levels of MMP-2 and MMP-9 were assessed by gelatin zymography in GBM cells under aerobic conditions (blank column) and hypoxia $\left(0.6 \% \mathrm{O}_{2}\right.$, black column) for $48 \mathrm{~h}$. Integrated intensities of gelatin digested bands were quantified and expressed in arbitrary units. Data are expressed as means $\pm \mathrm{SE},(\mathrm{n}=4)$. P-value of significance was determined using unpaired t-test or Mann-Whitney rank-sum test. MMP, matrix metalloproteinase; GBM, glioblastoma multiforme.

different GBM cell lines with abundance of the angiostatin $(\mathrm{K} 1-3 ; 38-\mathrm{kDa})$ isoform under both aerobic and hypoxic conditions, despite controversial reported differences in the anti-angiogenic potencies of angiostatin isoforms using recombinant angiostatin $(30,44,45)$. No significant differences in the percentages of detected angiostatin isoforms in the different 
A
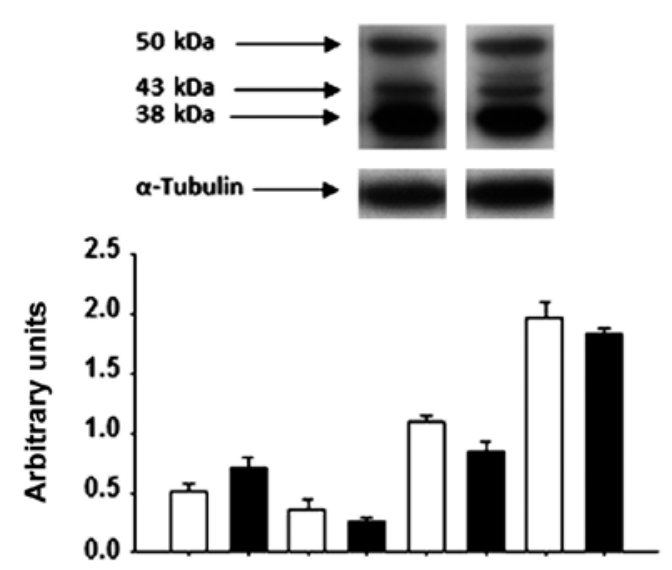

C
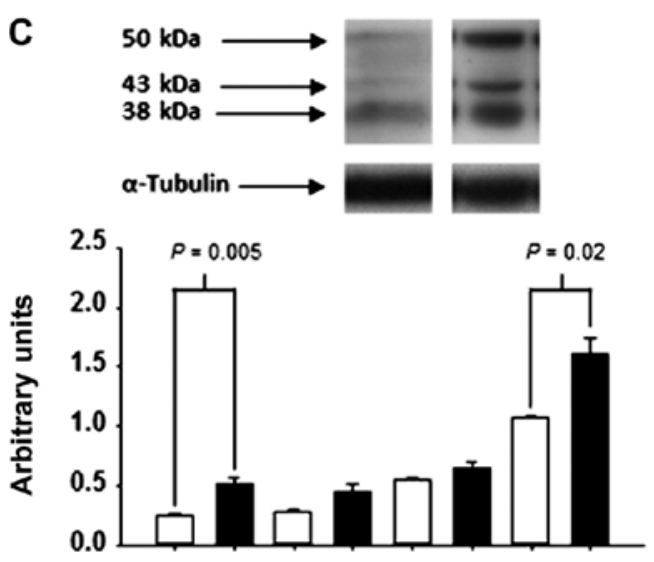

E
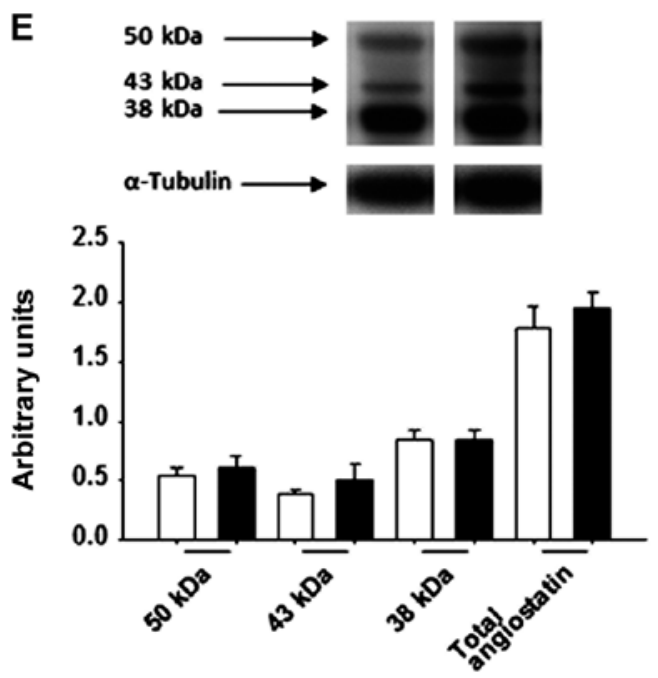

B
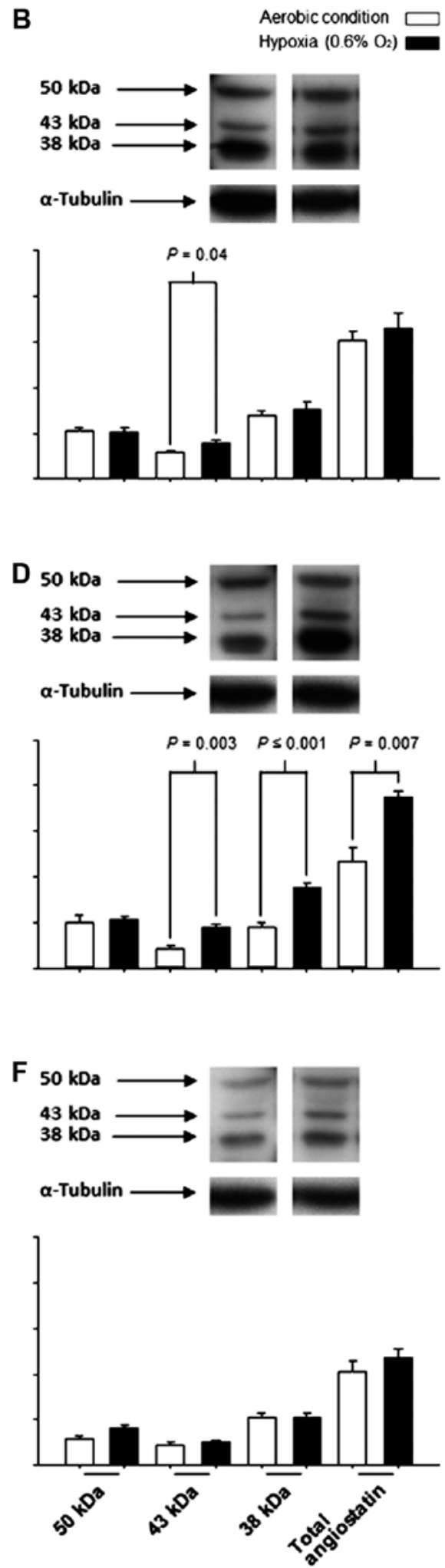

Figure 2. Representative western blot analyses and levels of angiostatin isoforms (50, 43 and 38 kDa). (A) M006x, (B) M059J, (C) M059K, (D) M010b, (E) U87R and (F) U87T cells. Angiostatin isoforms and $\alpha$-tubulin (loading control) were determined by western blot analyses in GBM cells under aerobic conditions (blank column) and hypoxia $\left(0.6 \% \mathrm{O}_{2}\right.$, black column) for $48 \mathrm{~h}$. Integrated intensities of angiostatin bands and $\alpha$-tubulin were quantified and expressed in arbitrary units. Normalized angiostatin levels are expressed as means $\pm \mathrm{SE}(\mathrm{n}=4)$. P-value of significance was determined using unpaired t-test or Mann-Whitney rank-sum test. GBM, glioblastoma multiforme.

GBM cell lines relative to total angiostatins under aerobic [K1-5 (33.4 $\pm 2.9 \%)$, K1-4 (20.4 $\pm 1.3 \%)$ and K1-3 (46.2 $\pm 1.8 \%)]$ and hypoxic conditions [K1-5 (31.8 $\pm 0.9 \%), \mathrm{K} 1-4(23.7 \pm 1.2 \%)$

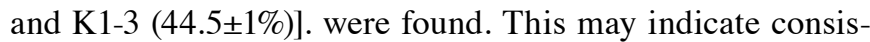
tent and comparable ratios of similarly expressed proteolytic enzymes under both conditions. Angiostatins were found to 


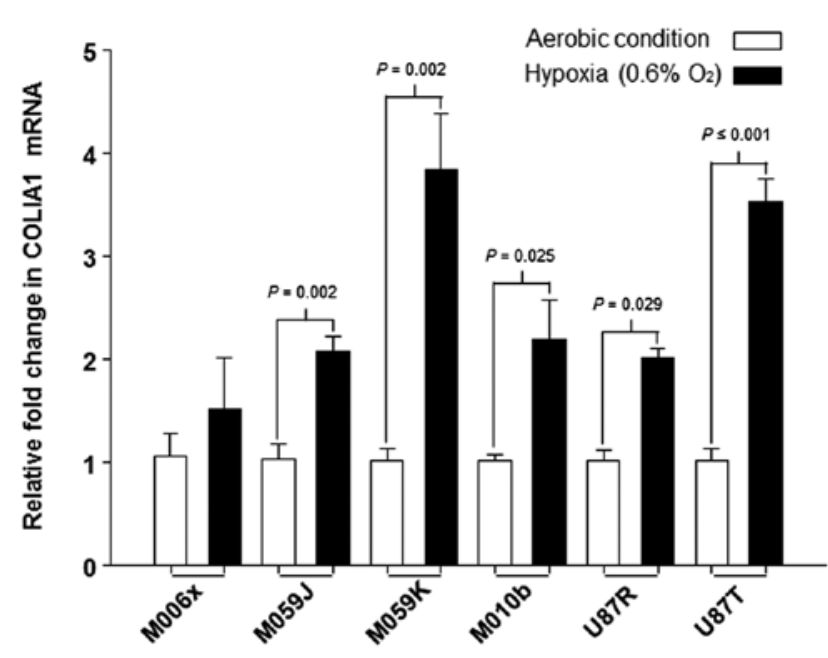

Figure 3. Effect of hypoxia on COLIA1 mRNA expression in GBM cell lines: M006x, M059J, M059K, M010b, U87R and U87T. COLIA1 mRNA expression was assessed by qRT-PCR in GBM cells under aerobic conditions and hypoxia exposure $\left(0.6 \% \mathrm{O}_{2}\right)$ for $48 \mathrm{~h}$. Data are expressed as means $\pm \mathrm{SE}(\mathrm{n}=4)$. P-value of significance was determined using unpaired t-test or Mann-Whitney rank-sum test. COLIA1, collagen type I $\alpha 1$; GBM, glioblastoma multiforme.

inhibit endothelial cell proliferation, migration, tube formation, and to induce apoptosis (reviewed in ref. 46), as well as inhibition of migration of cancer cells (22) that was noted earlier by unexplained observation of rapid growth of distant metastases following removal of the primary tumor (43).

In the present study, hypoxic upregulation of COLIA1 in most studied GBM cell lines may implicate COLIA1 as a mediator of angiogenesis. This has been supported by inhibition of collagen type-I and MMP synthesis by local silicone implants coated with halofuginone, an angiogenesis inhibitor (19), as well as induction of membrane type-1 MMP by COLIA1 that subsequently mediates the activation of pro-MMP-2 $(19,20)$. This contradicts others who reported that COLIA1 is inversely correlated with the histopathological grade of glioma (18) and overexpression of COLIA1 in T98G glioma cells suppresses cell proliferation and invasiveness and arrests tumor formation in vivo (17).

Controversial correlations were reported between the levels of angiostatins and histopathological grades in different tumors (47,48), while MMP-2, MMP-9 (49,50) and COLIA1 (18) were found to be correlated positively and negatively with the degree of malignancy of gliomas, respectively. In the present study upregulation of these parameters was noted in different GBM cells (grade IV gliomas), under $0.6 \% \mathrm{O}_{2}$ which simulated a moderate hypoxia in the GBM tumors (51). Additionally, we showed hypoxic upregulation of CD133 that has been reported to increase in GBM cells under hypoxia (34) and correlates positively with pathological grades of astrocytomas (33). However, lack of significant correlations between CD133 levels and other parameters (MMP-2, MMP-9, angiostatin isoform, and COLIA1) may indirectly imply that hypoxic upregulation of these parameters is not stem cell-specific but is a common property of all cells in different GBM cell lines.

In conclusion, hypoxia has been strongly implicated in tumor development, growth and angiogenesis (7) where hypoxia-induced necrosis and neovascularization are funda-

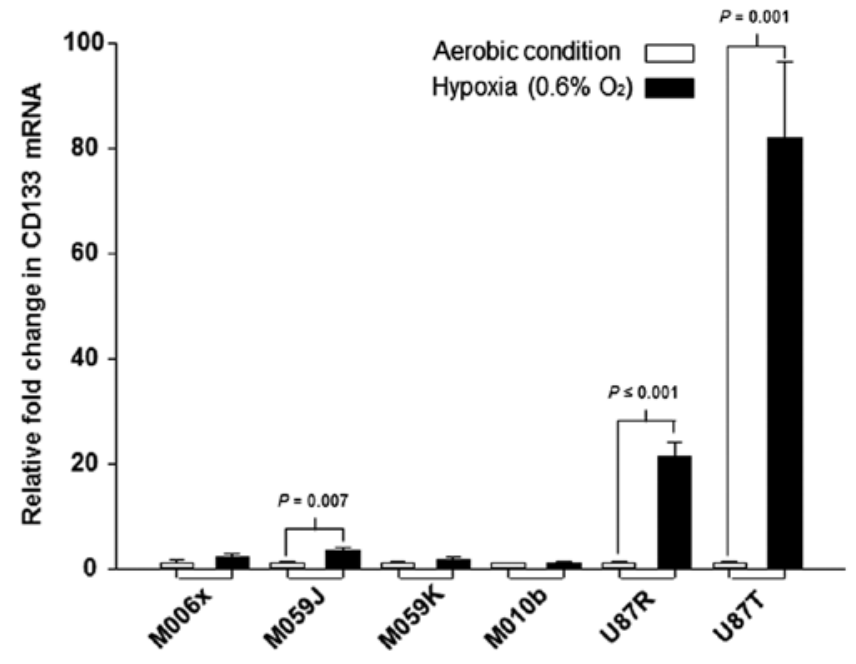

Figure 4. Effect of hypoxia on CD133 mRNA expression in GBM cell lines: M006x, M059J, M059K, M010b, U87R and U87T. CD133 mRNA expression was assessed by qRT-PCR under aerobic conditions and hypoxia exposure $\left(0.6 \% \mathrm{O}_{2}\right)$ for $48 \mathrm{~h}$. Data are expressed as means $\pm \mathrm{SE}(\mathrm{n}=4)$. P-value of significance was determined using unpaired t-test or Mann-Whitney rank-sum test. GBM, glioblastoma multiforme.

mental features for the pathological diagnosis of GBM tumors (6). The relative small number of reported anti-angiogenic factors compared with a larger number of pro-angiogenic ones, and dependence of tumor growth and metastasis on neovascularization has made anti-angiogenic strategies for cancer treatment an essential and a necessary concomitant strategy with surgical treatment. This is to substitute angiostatins expressed by tumor cells and/or angiostatins generated from circulating plasminogen by proteolytic enzymes (e.g. MMPs) secreted by tumor cells.

\section{Acknowledgements}

We thank Mrs. Bonnie Andrais for assistance with the tissue culture. The present study was supported by an award from the Canadian Cancer Society Research Institute with funds provided by the Canadian Cancer Society.

\section{References}

1. Vailhé B, Vittet D and Feige JJ: In vitro models of vasculogenesis and angiogenesis. Lab Invest 81: 439-452, 2001.

2. Bouïs D, Kusumanto Y, Meijer C, Mulder NH and Hospers GA: A review on pro- and anti-angiogenic factors as targets of clinical intervention. Pharmacol Res 53: 89-103, 2006.

3. Folkman J: Angiogenesis in cancer, vascular, rheumatoid and other disease. Nat Med 1: 27-31, 1995.

4. Chen J, McKay RM and Parada LF: Malignant glioma: lessons from genomics, mouse models, and stem cells. Cell 149: 36-47, 2012.

5. Stupp R, Mason WP, van den Bent MJ, et al: Radiotherapy plus concomitant and adjuvant temozolomide for glioblastoma. N Engl J Med 352: 987-996, 2005.

6. Bar EE: Glioblastoma, cancer stem cells and hypoxia. Brain Pathol 21: 119-129, 2011.

7. Semenza GL: Defining the role of hypoxia-inducible factor 1 in cancer biology and therapeutics. Oncogene 29: 625-634, 2010.

8. Liabakk NB, Talbot I, Smith RA, Wilkinson K and Balkwill F: Matrix metalloprotease 2 (MMP-2) and matrix metalloprotease 9 (MMP-9) type IV collagenases in colorectal cancer. Cancer Res 56: 190-196, 1996. 
9. O'Reilly MS, Wiederschain D, Stetler-Stevenson WG, Folkman J and Moses MA: Regulation of angiostatin production by matrix metalloproteinase-2 in a model of concomitant resistance. J Biol Chem 274: 29568-29571, 1999.

10. Patterson BC and Sang QA: Angiostatin-converting enzyme activities of human matrilysin (MMP-7) and gelatinase B/type IV collagenase (MMP-9). J Biol Chem 272: 28823-28825, 1997.

11. Vu TH and Werb Z: Gelatinase B: Structure, regulation, and function. In: Matrix Metalloproteinses. Parks WC and Mecham RP (eds). Academic Press, San Diego, pp122-124, 1998.

12. Adya R, Tan BK, Punn A, Chen J and Randeva HS: Visfatin induces human endothelial VEGF and MMP-2/9 production via MAPK and PI3K/Akt signalling pathways: novel insights into visfatin-induced angiogenesis. Cardiovasc Res 78: 356-365, 2008.

13. Kolli-Bouhafs K, Boukhari A, Abusnina A, et al: Thymoquinone reduces migration and invasion of human glioblastoma cells associated with FAK, MMP-2 and MMP-9 down-regulation. Invest New Drugs 30: 2121-2131, 2012.

14. Miller EJ and Gay S: Collagen: an overview. Methods Enzymol 82: 3-32, 1982.

15. Burgeson RE and Nimni ME: Collagen types. Molecular structure and tissue distribution. Clin Orthop Relat Res 282: 250-272, 1992

16. Paulus W: Brain extracellular matrix, adhesion molecules, and glioma invasion. In: Brain Tumor Invasion: Biological, Clinical, and Therapeutic Considerations. Mikkelsen T, Bjerkvig R, Laerum OD and Rosenblum ML (eds). Wiley-Liss, New York, pp301-322, 1998.

17. Honma K, Miyata $\mathrm{T}$ and Ochiya T: Type I collagen gene suppresses tumor growth and invasion of malignant human glioma cells. Cancer Cell Int 7: 12, 2007.

18. Savaraj N, Wu C, Landy H, et al: Procollagen alpha 1 type 1: a potential aide in histopathological grading of glioma. Cancer Invest 23: 577-581, 2005

19. Jordan MC and Zeplin PH: Local inhibition of angiogenesis by halofuginone coated silicone materials. J Mater Sci Mater Med 23: 1203-1210, 2012

20. Borrirukwanit K, Lafleur MA, Mercuri FA, et al: The type I collagen induction of MT1-MMP-mediated MMP-2 activation is repressed by $\alpha \mathrm{V} \beta 3$ integrin in human breast cancer cells. Matrix Biol 26: 291-305, 2007.

21. Twining SS, Wilson PM and Ngamkitidechakul C: Extrahepatic synthesis of plasminogen in the human cornea is up-regulated by interleukins-1alpha and -1beta. Biochem J 339: 705-712, 1999.

22. Zhang W, Fulci G, Buhrman JS, et al: Bevacizumab with angiostatin-armed oHSV increases antiangiogenesis and decreases bevacizumab-induced invasion in U87 glioma. Mol Ther 20: $37-45,2012$.

23. Jain RK, di Tomaso E, Duda DG, Loeffler JS, Sorensen AG and Batchelor TT: Angiogenesis in brain tumours. Nat Rev Neurosci 8: 610-622, 2007.

24. Murray D, Mirzayans R, Scott AL and Allalunis-Turner MJ Influence of oxygen on the radiosensitivity of human glioma cell lines. Am J Clin Oncol 26: e169-e177, 2003.

25. Allalunis-Turner MJ, Franko AJ and Parliament MB: Modulation of oxygen consumption rate and vascular endothelial growth factor mRNA expression in human malignant glioma cells by hypoxia. Br J Cancer 80: 104-109, 1999.

26. Allalunis-Turner MJ, Barron GM, Day RS III, Dobler KD and Mirzayans R: Isolation of two cell lines from a human malignant glioma specimen differing in sensitivity to radiation and chemotherapeutic drugs. Radiat Res 134: 349-354, 1993.

27. Johnston AL, Lun X, Rahn JJ, et al: The p75 neurotrophin receptor is a central regulator of glioma invasion. PLoS Biol 5 e212, 2007.

28. Koch CJ, Howell RL and Biaglow JE: Ascorbate anion potentiates cytotoxicity of nitro-aromatic compounds under hypoxic and anoxic conditions. Br J Cancer 39: 321-329, 1979.

29. Emara $M$ and Cheung PY: Inhibition of sulfur compounds and antioxidants on MMP-2 and -9 at the activity level found during neonatal hypoxia-reoxygenation. Eur J Pharmacol 544: 168-173, 2006.

30. Soff GA: Angiostatin and angiostatin-related proteins. Cancer Metastasis Rev 19: 97-107, 2000.
31. Kim KS, Kim DS, Chung KH and Park YS: Inhibition of angiogenesis and tumor progression by hydrodynamic cotransfection of angiostatin K1-3, endostatin, and saxatilin genes. Cancer Gene Ther 13: 563-571, 2006.

32. Emara M, Obaid L, Johnson S, Bigam DL and Cheung PY: Expression of angiostatin and its related factors in the plasma of newborn pigs with hypoxia and reoxygenation. Arch Biochem Biophys 466: 136-144, 2007.

33. Ma YH, Mentlein R, Knerlich F, Kruse ML, Mehdorn HM and Held-Feindt J: Expression of stem cell markers in human astrocytomas of different WHO grades. J Neurooncol 86: 31-45, 2008.

34. Griguer CE, Oliva CR, Gobin E, et al: CD133 is a marker of bioenergetic stress in human glioma. PLoS One 3: e3655, 2008.

35. Fischer I, Gagner JP, Law M, Newcomb EW and Zagzag D: Angiogenesis in gliomas: biology and molecular pathophysiology. Brain Pathol 15: 297-310, 2005.

36. Semenza GL: Targeting HIF-1 for cancer therapy. Nat Rev Cancer 3: 721-732, 2003.

37. Valter MM, Hügel A, Huang HJ, et al: Expression of the Ets-1 transcription factor in human astrocytomas is associated with Fms-like tyrosine kinase-1 (Flt-1)/vascular endothelial growth factor receptor-1 synthesis and neoangiogenesis. Cancer Res 59: 5608-5614, 1999

38. Loeffler S, Fayard B, Weis J and Weissenberger J: Interleukin-6 induces transcriptional activation of vascular endothelial growth factor (VEGF) in astrocytes in vivo and regulates $V E G F$ promoter activity in glioblastoma cells via direct interaction between STAT3 and Sp1. Int J Cancer 115: 202-213, 2005.

39. Kondraganti S, Mohanam S, Chintala SK, et al: Selective suppression of matrix metalloproteinase-9 in human glioblastoma cells by antisense gene transfer impairs glioblastoma cell invasion. Cancer Res 60: 6851-6855, 2000.

40. Lolmède K, Durand de Saint Front V, Galitzky J, Lafontan M and Bouloumié A: Effects of hypoxia on the expression of proangiogenic factors in differentiated 3T3-F442A adipocytes. Int J Obes Relat Metab Disord 27: 1187-1195, 2003.

41. Muir EM, Adcock KH, Morgenstern DA, et al: Matrix metalloproteases and their inhibitors are produced by overlapping populations of activated astrocytes. Brain Res Mol Brain Res 100: 103-117, 2002

42. Valtz NL, Hayes TE, Norregaard T, Liu SM and McKay RD: An embryonic origin for medulloblastoma. New Biol 3: 364-371, 1991.

43. O'Reilly MS, Holmgren L, Shing Y, et al: Angiostatin: a novel angiogenesis inhibitor that mediates the suppression of metastases by a Lewis lung carcinoma. Cell 79: 315-328, 1994.

44. Cao R, Wu HL, Veitonmäki N, et al: Suppression of angiogenesis and tumor growth by the inhibitor K1-5 generated by plasminmediated proteolysis. Proc Natl Acad Sci USA 96: 5728-5733, 1999.

45. MacDonald NJ, Murad AC, Fogler WE, Lu Y and Sim BK: The tumor-suppressing activity of angiostatin protein resides within kringles 1 to 3. Biochem Biophys Res Commun 264: 469-477, 1999.

46. Wahl ML, Kenan DJ, Gonzalez-Gronow M and Pizzo SV: Angiostatin's molecular mechanism: aspects of specificity and regulation elucidated. J Cell Biochem 96: 242-261, 2005.

47. Murthi P, Barker G, Nowell CJ, et al: Plasminogen fragmentation and increased production of extracellular matrix-degrading proteinases are associated with serous epithelial ovarian cancer progression. Gynecol Oncol 92: 80-88, 2004.

48. Yabushita H, Noguchi M, Kinoshita S, Kishida T, Sawaguchi K and Noguchi M: Angiostatin expression in endometrial cancer. Oncol Rep 9: 1193-1196, 2002.

49. Wang M, Wang T, Liu S, Yoshida D and Teramoto A: The expression of matrix metalloproteinase-2 and -9 in human gliomas of different pathological grades. Brain Tumor Pathol 20: 65-72, 2003.

50. Fillmore HL, VanMeter TE and Broaddus WC: Membrane-type matrix metalloproteinases (MT-MMPs): expression and function during glioma invasion. J Neurooncol 53: 187-202, 2001.

51. Evans SM, Judy KD, Dunphy I, et al: Comparative measurements of hypoxia in human brain tumors using needle electrodes and EF5 binding. Cancer Res 64: 1886-1892, 2004. 